\title{
PERFORMANCE, ORGANISATION AND INEQUALITY IN EDUCATION SYSTEMS: AN INTERNATIONAL COMPARISON OF THE DYNAMICS OF SCHOOLING
}

\author{
Susana da Cruz Martins \\ ${ }^{1}$ Asst. Prof., Instituto Universitário de Lisboa (ISCTE-IUL), Centro de Investigação e Estudos de \\ Sociologia (CIES-IUL), and Gulbenkian Professorship, PORTUGAL, susana.martins@iscte.pt
}

\begin{abstract}
The aim of this article is to identify the main dynamics of education from a transnational and trans-regional perspective. It therefore takes a diachronic approach over a time span of more than half a century and consider the meanings of different categories in the process, in particular where age and gender are concerned. It also takes account of the weight of education and its dynamics and locations in social opportunities and their relationship with different types of inequality.

The first interpretative axis focuses on the most significant moments of enlargement and relates them to inequalities in education. In spite of a gradual increase in access to and certification of education and training systems over more than half a century, we still find inequality in education and associated with other spheres, such as age/generation and gender, at regional and national level.

The second analytical axis is on education systems' ability to operate in these dynamics. We look at how they have been creating policies and cultures that offer incentives or, on the other hand, use dissuasive mechanisms that result in real difficulties in producing basic skills and sustainable learning paths enabling people to make their way in knowledge-based societies and economies.

Finally, we also seek to establish a relationship between inequality and the fundamental guidelines in education systems. This relationship is reflected in the systems' performance and the integration and success of students of different social origins.

The findings point to a relationship between education and life opportunities and the way in which education systems foster greater equity in the success and construction of school paths. The references and empirical sources used include the OECD, UNESCO, etc. They helped us to delve further into these issues and make comparisons between countries and regions, in diachronic perspective.
\end{abstract}

Keywords: Comparative education; educational inequalities; educational expansion; success and retention.

\section{PRELIMINARY NOTES}

The qualifications constitute one of the most determinant elements of knowledge-based societies and economies. In this sense, one of the main aims of this study is to examine the dynamics and extent of this expansion in various regions around the world, beginning in the mid- $20^{\text {th }}$ century. The first line of analysis 
describes the gradual increase in educational systems' ability to promote access and certification, with a history that dates back more than half a century. This characterization is associated with a reading of educational inequality as being related to other inequalities, such as regional and national inequalities and inequalities that are related to age/generation and gender. A second line of analysis is related to the ability and performance of educational systems to operate in these dynamics. How is it that these systems have created policies and cultures that are capable of pushing students ahead or holding them back but have difficulty creating basic skills and providing steady academic advancement to prepare them to function in a knowledge-based society and economy?

Some of the classic questions of sociology of education remain relevant to the analysis of inequalities that have been developed through the spread of educational and training systems. This relevance appears to vary, however, when different countries and regions are compared. In this type of analytical exercise, we find educational systems, which are key institutions of modernity, that are out-of-step with each other, reinforcing dynamics of speeding students up or holding them back in their schooling. It is also important to investigate the relationship between these mechanisms and the social inequalities found there.

The present study follows a methodology of extensive comparative analysis with a multi-level perspective and is based on a transnational approach and comparison among countries. The analyses are conducted using statistical data from international sources such as UNESCO and OECD.

\section{THEORETICAL AND ANALYTICAL PERSPECTIVES}

The theoretical and analytical perspective presented here examines the expansion of education in various regions of the world as well as generational and gender inequalities in the manner in which schooling is implemented, both between countries and within countries (Barro and Lee, 2015; Benaabdelaali et al., 2012). As is known, these dynamics and inequalities are decisive in determining individuals' access to the opportunities, patterns of life, and resources that education confers (Breen et al., 2009, 2010; Martins et al., 2014; Werfhorst, 2007).

If it is true that inequality in educational opportunities closely mirrors social inequalities (the classic references for which are, e.g., Coleman, 1996; Bourdieu and Passeron, 1964; Boudon, 1981; Bernstein, 1975 ), then it is also true that this is manifested in ways that vary greatly from country to country (DuruBellat, Mons, Suchaut, 2004), though their institutional forms indicate, at least on initial examination, a certain isomorphism (Meyer, Ramirez, Frank and Schofer, 2006). The reason is that in many countries, inequality is woven into the very fabric and form of the institutions (Martins, 2012, 2013).

With regard to educational inequality, we come upon stratification mechanisms, which have been the subject of extensive study by educational sociologists, that influence both access to education and successful progress, marking what we typically call the unequal "tracking" of students into particular educational paths and opportunities (Martins, 2013). Schools can certainly leverage social mobility; however, they can maintain unequal social structures. Educational policies and organizational and pedagogical models that favour equity and educational mobility can certainly act as shock absorbers to cushion inequality; however, by reinforcing inequality in the form of very hierarchical and selective educational systems, acting in concert with an unequal social structure, schools can contribute to a boomerang effect of these inequalities perpetuating and reinforcing an unequal distribution of resources.

\section{ANALYSIS OF THE INEQUALITIES, ORGANIZATION, AND PERFORMANCE OF EDUCATIONAL SYSTEMS: A COMPARATIVE PERSPECTIVE}

\subsection{Global Dynamics And Inequalities In Education}

Whenever a country or region experiences a period of accelerated growth in education, the segments of society that are not included in its implementation are left in a more unequal position, cut off from educational resources and the opportunities that are provided by education.

As can be observed, formal schooling has spread quickly since the 1960 s, with some locations also experiencing surges in the 1980s and 1990s, and has recently tapered off. Since the first decade of the $21^{\text {st }}$ century, we have entered a phase of greater global stability and a clearer regional definition of educational hierarchies in terms of their dynamics and measures (see Fig. 1). 
Upon close analysis of Fig. 1, we observe that countries with developed or advanced economies (especially Western Europe and North America) and Europe and Central Asia appear on the upper part of the graph, indicating that they are better positioned in terms of the spread of education.

At the bottom of the graph appear the lines showing the evolution of areas such as Sub-Saharan Africa and South Asia, indicating dynamics that are comparatively weak on an international scale. Despite the improvements that have been observed in these regions, which are especially pronounced since the 1980s, these areas do not appear to be catching up to the advances that have been made in other regions.

The remaining regions such as Latin America, East Asia and the Middle East and North Africa, which are slightly lower on the trend lines in Fig. 1, occupy intermediate positions.

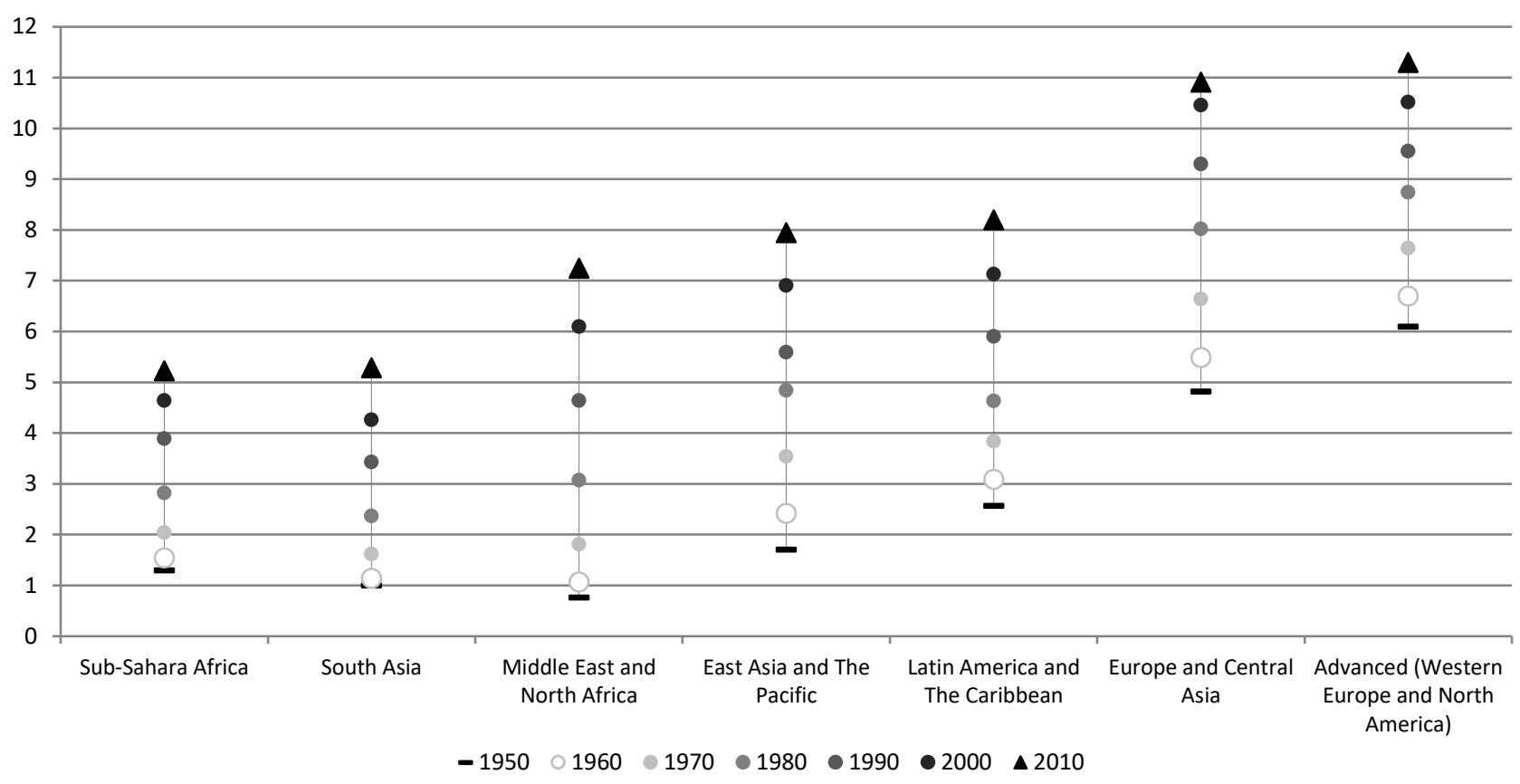

Fig. 1 Evolution of average years of schooling completed, shown by regions, 1960-2012 (population aged 25 or older)

Note: Calculation method used by UNESCO and Barro and Lee (2010).

Source: Built from UNESCO Institute for Statistics (2015), Barro and Lee (2014)

It is worth adding to this analysis an index that assumes a concession of distributional inequality (a coefficient), a type of educational Gini coefficient. In global terms, educational inequalities were much more pronounced in the 1950s, both within regions and among regions. Beginning in the 1980s, largely due to the spread of educational systems, schooling is much more evenly distributed, with Europe and Central Asia providing the best examples of this recovery (Fig. 2). The distribution of education was more unequal among females than among males. This phenomenon may have to do with the fact that at the starting point of this study (1950), females were rarely educated whereas, in recent years, the trend of education has been stronger among young females than among young males. This difference remains important for South Asia countries but is not relevant for regions such as Latin America, North America, Europe and Central Asia.

On a regional scale, both Western European and North American countries show a marked, steady trend of diminishing educational inequality over more than 50 years. The reduction is higher, however, among males than among females (Fig. 2).

However, the disparities between males and females are not as pronounced in Latin America and the Caribbean, where they have decreased significantly since 1980 as the result of an educational expansion that lagged slightly behind Western Europe and North America (which are grouped here under the category of advanced countries) and Europe and Central Asia (Fig. 2). 


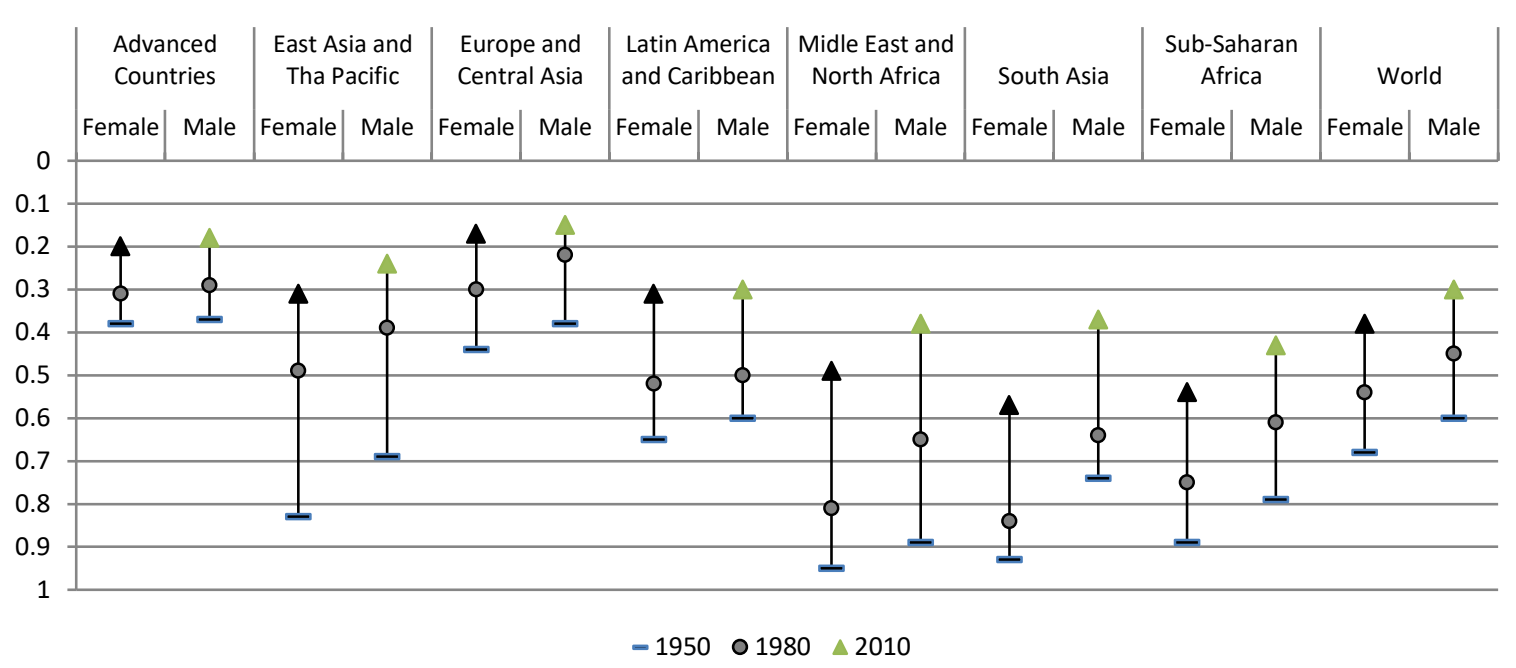

Fig. 2 Educational Gini coefficient, by world regions and by gender, 1950-2010. (Population aged 15 and older - range from 0 to 1 )

Source: Built from Benaabdelaali et al (2012).

The educational structures vary greatly among the different countries of the OECD. As we have observed, some of these differences have been more persistent. Fig. 3 shows a top-ranking group composed of Eastern European, North American, and some Northern European countries where approximately $90 \%$ of the population has secondary or higher education, which is consistent with a previous study of European countries (Martins, 2012). Some Latin American and Southern European countries are catching up (visible in the population aged between 25 and 34 years), but the proportion of their populations (aged 25 to 64 years) with secondary education is less than $60 \%$.

It may also be observed that the countries lagging furthest behind in secondary education show relatively strong progress among the youngest generation. Considering the current distribution shown in Fig. 4, one of the basic questions that comes to mind is how the stock of secondary school graduates in each country affects their access to resources, namely, financial resources.

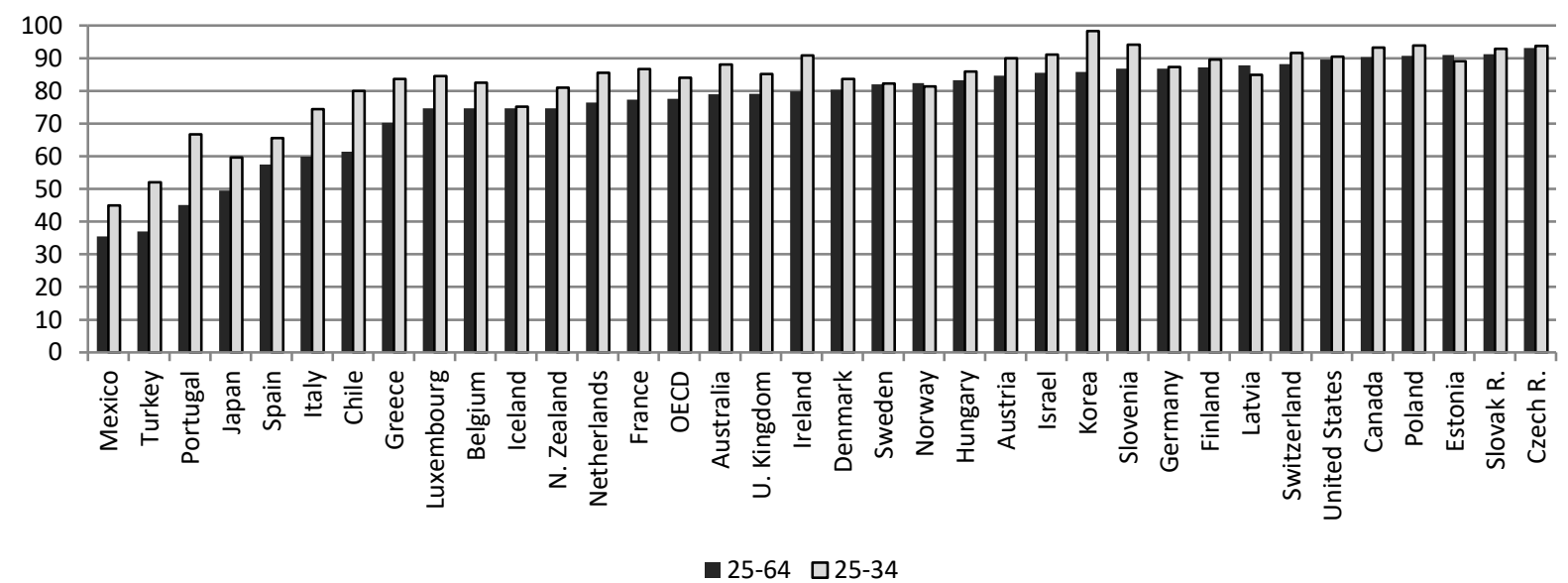

Fig. 3 Population with secondary education or higher, OECD countries, 2015 (\%) Population aged 2564 years and aged $30-34$ years.

Source: OECD (2016), Education at a Glance, Table A1.3.

An initial reading of Fig. 4 leads to the conclusion that in all the OECD countries, the level of education is related to the level of earned income. The higher the level of education is, the higher the income (as has 
been shown by Martins et al., 2014). In some Latin American and Eastern European, these differences are more pronounced, reflecting very unequal societies.

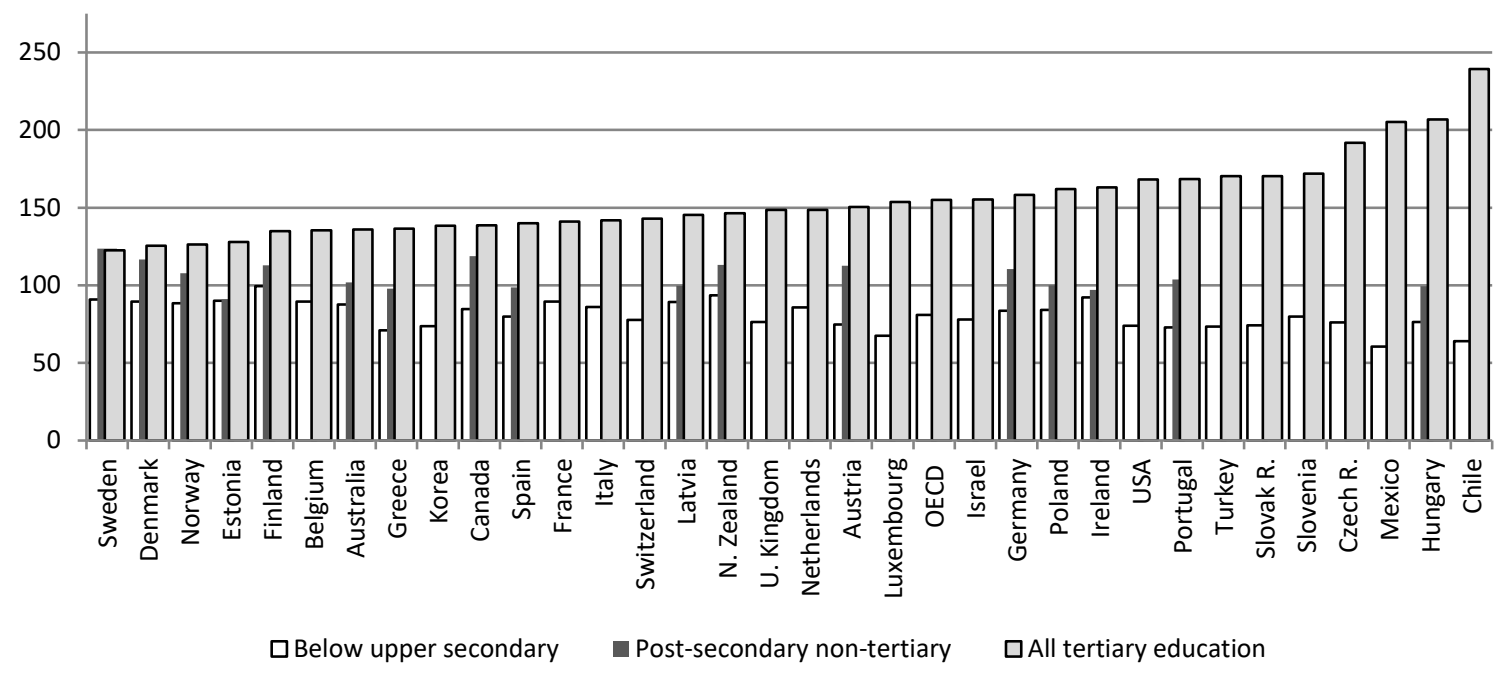

Fig. 4 Income of the employed population by level of education, OECD countries, 2014. Population with income from employment; Secondary education (ISCED 3) $=100$

Source: OCDE (2016), Education at a Glance, Table A6.2a.

Note: Belgium, Canada, Chile, Czech R., Finland, Luxembourg, and Spain: 2013; Austrália, France, Italy and

Sweden: 2012; and Netherlands: 2010

The breakdown of earnings as related to education is also very revealing in some less educated countries but with the additional factor that only a small portion of the population sees improvements to their earnings through this route.

\subsection{Educational Systems: Performance And Directions}

This section turns to an analysis of how educational systems change or reinforce long-standing inequalities.

Paradoxically, the school systems of the countries that lag furthest behind in education in many cases act as a hindrance to academic progress through the practice of requiring students to repeat a grade level. This practice of retaining students, often as a corrective for academic failure, is most common in Southern European countries such as Portugal and Spain, in a context of centralized procedures and operating rules (Martins, 2012), in addition to Belgium, Luxembourg, and France. On the other end of the spectrum are countries where retention is an exception to the rule, especially in Northern Europe (Norway, Iceland, Finland, Sweden, and Denmark), the United Kingdom, Eastern Europe (Slovenia, Estonia, Poland, and the Czech Republic), some Asian countries (such as Japan and South Korea), and Israel and Greece.

Many of the differences in the practice and administration of school retention is not even written into the policies and laws that govern this type of procedure. Finland and Portugal, for example, have similar laws governing retention but very different institutional and educational cultures and practices (Eurydice, 2011).

Fig. 5 addresses two analytical issues. First, one can say that there is no linear correlation between the retention rate and the educational level of parents of 15 year olds. The rate at which students are retained is much more closely related to the selectivity of the educational systems that employ academic retention mechanisms than it is to the prevailing social contexts (e.g., The Netherlands, France and Belgium have negligible rates of less-educated parents). However, although no direct relationship can be proven, countries with higher rates of less-educated parents have retention rates that are higher than the OECD average. See also Turkey and Mexico (which have the highest percentage of parents with primary schooling) as well as Portugal (where higher retention rates are associated with parents' low educational levels). In these countries, the long history of retention policies may also contribute to the parents' generation having a history of academic difficulties because their school years were most likely also marked by the practice of retention; on the other hand, less educated parents tend to have difficulty helping their children successfully overcome such obstacles. 


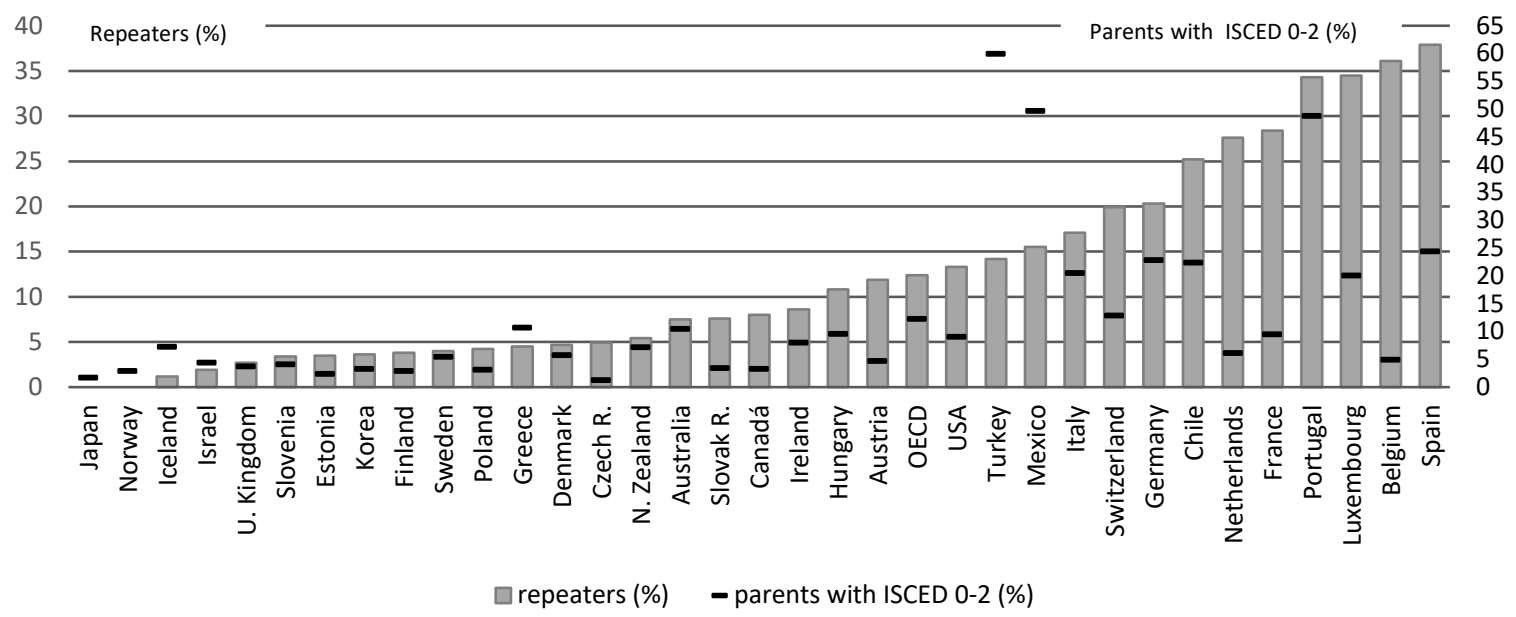

Fig. 5 Repetion rate (\%) and parents (of 15 year olds) with lower secondary education (ISCED 0-2) (\%), in OECD countries, 2012

Source: Built from OECD (2013), Data from PISA2012 (Vol. IV).

The indicator for performance in math proposed by the OECD Programme for International Student Assessment (PISA) tests 15 year olds from various countries for competence in this subject. The average score on the OECD assessment is 494, and 16 countries have performance levels that are higher than 500 - most of them being in Northern and Central Europe, Canada, Japan, and South Korea (the last two having the highest average scores) (Fig. 6). However, although previous versions of the PISA assessment showed pronounced differences between the math scores of student from Portugal and those of students from other countries, Portuguese students have been closing the gap with countries that score higher on the PISA assessments. This improvement certainly has accompanied reforms in the organization of teaching and learning. In Sweden, where changes appear to be liberalizing educational policy, students have shown signs of scoring lower on math competency tests. Latin American countries have had the worst performance on the PISA, with students achieving the lowest scores on international math tests.

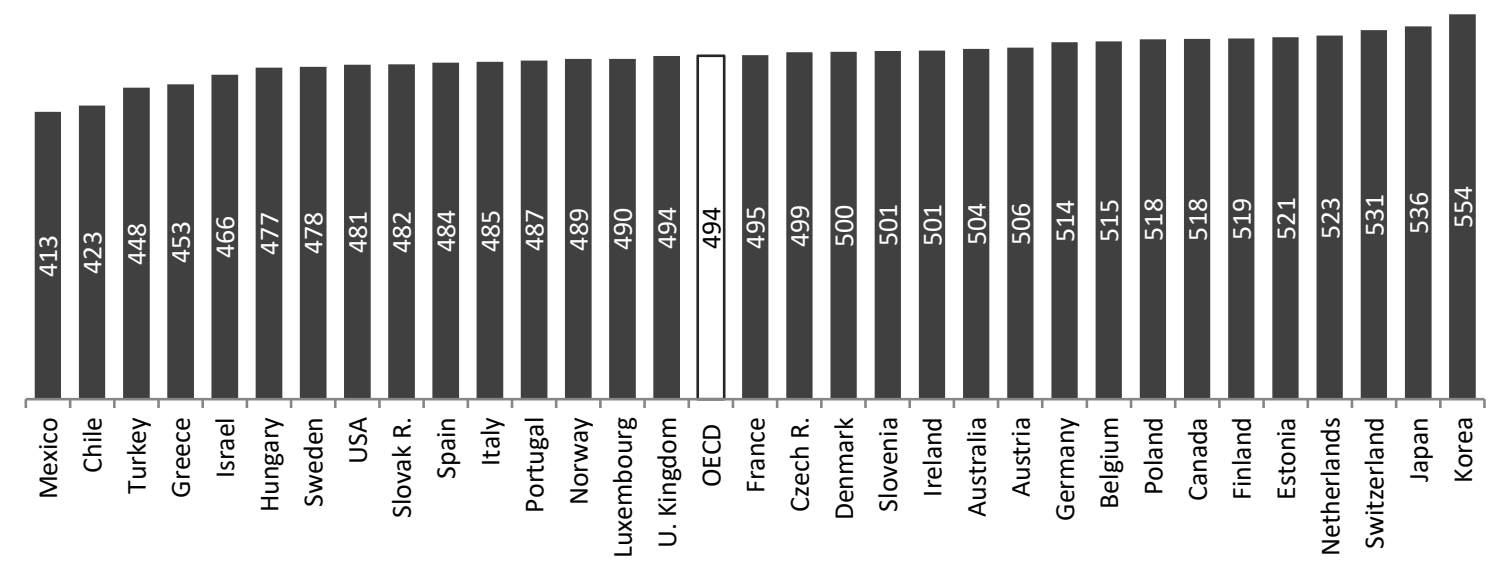

Fig. 6 Performance on the 2012 PISA math (average scores)

Source: OECD (2014), PISA data for 2012 (Vol. I).

In relation to educational inequalities, it may be said that the mechanisms of stratification noted above translate into inequalities in academic performance in the educational systems and are reflected in different academic courses and educational opportunities (Fig.7). 


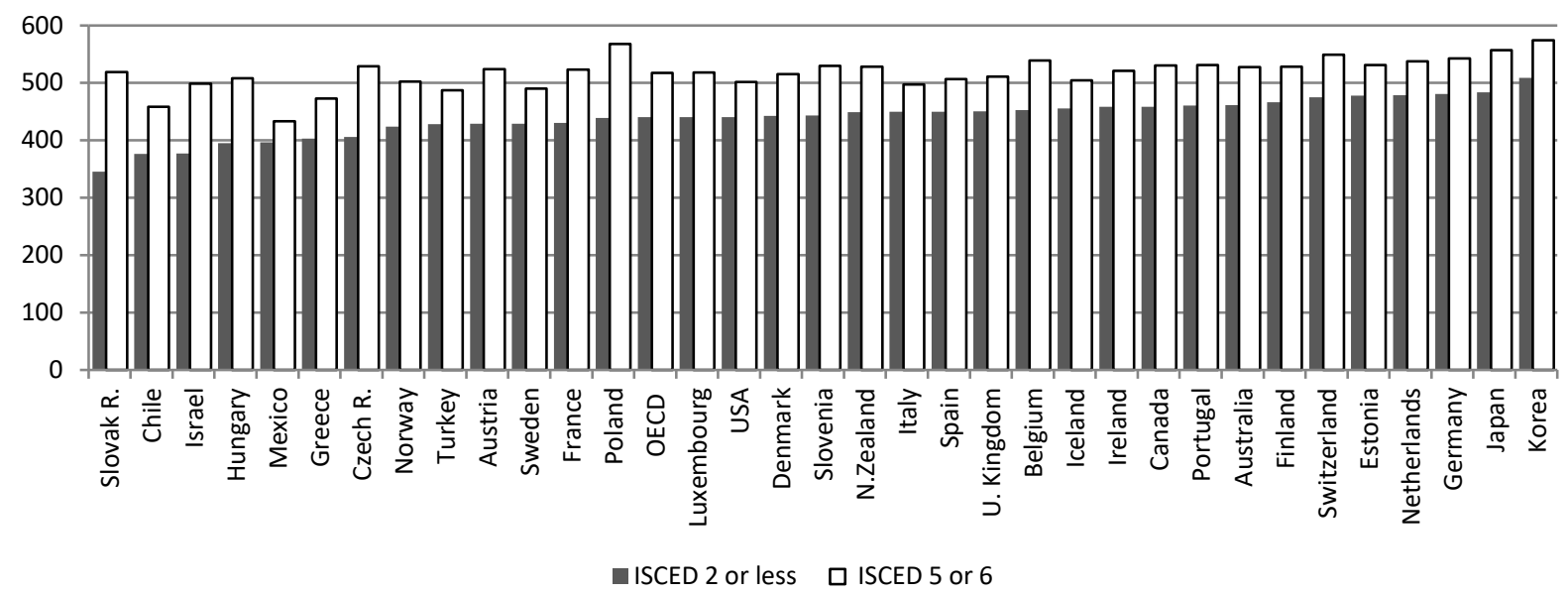

Fig. 7 Performance on the 2012 PISA math (average scores) according to parents' educational levels in OECD countries, 2012

Source: OECD (2013), PISA data for 2012 (Vol. IV).

In all of the countries shown in Figure 8, the children of more highly educated parents performed better on the PISA assessments. A similarly consistent pattern of inequality is found in Eastern European countries (such as Slovakia, Czech Republic, Hungary, and Poland). Even knowing that systemic social inequalities vary among countries and regions (Duru-Bellat and Suchaut, 2005), as patently observed here, some authors (Schlicht, Stadelmann-Steffen, and Freitag, 2010) have called attention to the fact that student performance is more dependent on their social background in Eastern European countries.

\section{CONCLUSIONS AND NEW QUESTIONS}

School openings have been effective in the world's different regions during the second half of the $20^{\text {th }}$ century and the early $21^{\text {st }}$ century. They have been able to handle the processes of broadening and reinforcement of school institutions over the past 60 years. Although they have highly varied dimensions, these openings have very important elements of social selectivity, revealing inequalities between genders, generations, and regions/countries. Regions such as Western Europe and North America have had unbalanced educational dynamics that are much faster and broader than their populations.

Educational systems are an expression of modern institutions, which, despite acknowledged isomorphism, denote logics of very differentiated tracking of school careers. One of the best indicators of such methods of action is the retention rate, which has served as a tool for hampering their populations' education. Such mechanisms have constituted one of the most serious obstacles to universal education and sustainable school careers that support equity. The most unequal have had weaker dynamics for educating the population.

The countries that display very unequal education patterns, even among young people, tend to have educational system that imprints processes that favour this inequality on their organizational logic and functioning (Martins, 2012). Associated with this analysis is the fact that these same systems are themselves more susceptible to incorporating aspects of social inequality into their organization and institutional patterns, making social inequality an integral part of the system itself, reflecting it in its social processes and historical bases - and ending up having a boomerang effect on inequalities. Such standardization is not impervious to change but is subject to temporal and spatial diversity that, at times, can transform itself and affect inequality itself.

Associated with such dynamics is the manner in which educational policies operate through academic selectivity, in which the organizational and pedagogical dimensions of schools treat diversity inclusively and, no less important, if there is a commensurate, systematic intervention of public and social policies to combat adverse living conditions. In this sense, school can act to cushion inequalities, or damper, and be a motor force for social mobility. Given that inequalities have a certain cumulative effect, the reduction of inequalities must be observed in the interaction of its various dimensions (Costa, 2012). Although public, social, and 
educational policies are not the only elements that are capable of transforming social and educational realities, they are certainly instruments to be taken into account in changing these systems.

\section{REFERENCE LIST}

Barro, J.R.; and Lee, J-W (2015). Education Matters global - School gains from the 19th to the 2st century. Oxford: Oxford University Press.

Benaabdelaali, W.; Hanchane, S.; and Kamal, A. (2012). A New Data Set of Educational Inequality in the World, 1950-2010: Gini Index of Education by Age Group. Cahiers du LEAD, № 2012-1, p. 1-24.

Bernstein, B. (1975). Language et Classe Social. Codes Socio-Linguistiques et Contrôle Social. Paris: Les Éditions de Minuit.

Boudon, R. (1981). A Desigualdade de Oportunidades. A Mobilidade Social nas Sociedades Contemporâneas. Brasília: Editora Universidade de Brasília.

Bourdieu, P.; and Passeron, J. P. Les Héritiers. Les Étudiants et la Culture. Paris : Les Éditions de Minuit, 1964.

Breen, R.; Luijkx, R., Müller; W., and Pollak; R. (2009). Non-persistent inequality in educational attainment: evidence from eight European countries. American Journal of Sociology, 114 (5), 1475-1521.

Breen, R., Luijkx, R., Müller, W., and Pollak, R. (2010). Long-term trends in educational inequality in Europe: class inequalities and gender differences. European Sociological Review, 26 (1), 1-18. DOI: 10.1093/esr/jcp001

Coleman, J. S. (org.) (1966). Equality of Educational Opportunity. Washington: DC, Government Printing Office.

Costa, A. F. (2012), Desigualdades Globais (Global inequalities). Sociologia, Problemas e Práticas, 68, 9-32. DOI: 10.7458/SPP20126869.

Duru-Bellat, M.; Mons, N.; \& Suchaut, B. (2004). Organisation scolaire et inégalités sociales de performance: les enseignements de l'enquête PISA. Education et Formations, 70, 123-131. (http://media.education.gouv.fr/file/13/5/5135.pdf).

Duru-Bellat, M., and Suchaut, B. (2005), Organisation and context, efficiency and equity of educational systems: what PISA tells us. European Educational Research Journal, 4(3), 181-194.

EURYDICE. (2011). Grade Retention During Compulsory Education in Europe: Regulations and Statistics. Brussels: European Comission. DOI: 10.2797/50570.

Martins, S. C. (2012). Escolas e Estudantes da Europa: Estruturas, Recursos e Políticas de Educação [Schools and Students in Europe]. Lisbon: Editora Mundos Sociais.

Martins, S. C. (2013). "Social state and public support for education: European dynamics and configurations", proceedings of the EDULEARN13 5th International Conference on Education and New Learning Technologies (Session: General Issues in Education. Barriers to Learning \& Globalization).

Martins, S. C.; Nunes, N.; Mauritti, R.; and COSTA, A.F. (2014). O que nos dizem as desigualdades educacionais sobre as outras desigualdades? Uma perspetiva comparada à escala europeia [What is the educational inequalities tell us about other inequalities? A compared perspective on a European scale]. In Melo, B.P.; A. Diogo; M. Ferreira; J. T. Lopes, e E. E. Gomes (orgs.). Entre Crise e Euforia : Práticas e Políticas Educativas no Brasil e em Portugal. Porto: Faculdade de Letras da Universidade do Porto, pp.845-868.

Meyer, J.; Ramirez, F. O.; Frank; e D. J; and Schofer, E. (2005). Higher education as an institution, CDDRL Working Papers, 57.

OECD (2016), Education at a Glance 2016: OECD Indicators, OECD Publishing, Paris. http://dx.doi.org/10.187/eag-2016-en

OECD (2014). PISA 2012 Results: What Students Know and Can Do - Student Performance in Mathematics, Reading and Science (Volume I, Revised edition, February 2014), PISA, OECD Publishing. http://dx.doi.org/10.1787/9789264201118-en). 
OECD (2013). PISA 2012 Results: Excellence Through Equity: Giving Every Student the Chance to Succeed (Volume II), OECD Publishing, 2013. ( http://dx.doi.org/10.1787/9789264201132-en).

OECD. 2013. PISA 2012 Results: What Makes Schools Successful? Resources, Policies and Practices (Volume IV), PISA , OECD Publishing. (http://dx.doi.org/10.1787/9789264201156-en).

Schlicht, R., Stadelmann-Steffen, I.; and Freitag, M. (2010), Educational inequality in the EU: The Effectiveness of the national education policy, European Union Politics, 11(1), 29-59. doi: $10.1177 / 1465116509346387$.

Werfhorst, H.G. van (2007). Scarcity and abundance: Reconciling trends in the effects of education on social class and earnings in Great Britain 1972-2003. European Sociological Review, 23 (2), 239-261. DOI: 10. 1093/esr/jc103. 